\title{
VICIOS DE LA LEY 1354 DE 2009
}

\author{
Oscar Arismendy Martínez \\ arismendymartinezoscar14@hotmail.com
}

\begin{abstract}
RESUMEN
Se trata de un ejercicio metodológico que elabora un examen a las discusiones judiciales surgidas a propósito de la promulgación de la ley 1354/09, consistente en plantear que legitimar la reelección vía referendo lastima profundamente la democracia -por lo tanto-, hay que considerar seriamente, la tesis de Bobbio y Ferrajoli, relacionada con el respeto a los procedimientos formales implícitos en la democracia, que son los que nos liberan de la tiranía de las supuestas mayorías.
\end{abstract}

Palabras claves: vicios de ley, análisis judicial, procedimientos formales, democracia

El Derecho Constitucional es una de las áreas de las ciencias jurídicas con grandes avances y desarrollos dogmáticos, pero sobre todo, ha servido como herramienta de cambio social. Se ha pensado en varios momentos que el derecho mismo es capaz de contrarrestar al capitalismo, nivelando la terrible iniquidad resultante de su racionalidad, pero luego se constata que a la vez se mantiene como un mecanismo protector del statu quo; al no proteger el orden existente, corre con el riesgo de ser transformado para obedecer a la dinámica del sistema. Esta situación se hizo evidente con las amenazas de reforma a la justicia en momentos coyunturales y de especial interés para el ejecutivo en su pretensión de aprobación de una enmienda constitucional que permitiera una segunda reelección inmediata en 2010 en nuestro país.

Examinar con propósitos académicos las decisiones judiciales, es un ejercicio que ha demostrado en la historia del derecho sus beneficios para las comunidades jurídicas e instituciones educativas. Las universidades a través de las facultades de derecho deben incidir en los rumbos que tome el sistema jurídico de un país, ya por vía de la investigación o a través de la formación de profesionales del derecho; en este marco, la sentencia del Tribunal Constitucional C-141/10, se convierte en un valioso instrumento pedagógico para las comunidades académicas del mundo jurídico. El impacto de las constituciones en el derecho y en las sociedades, sumado al valor pedagógico del estudio de la jurisprudencia por las comunidades académicas 
del derecho, son razones válidas y suficientes para justificar el presente trabajo que de manera concreta se expone a continuación.

Formulemos el interrogante de si se pueden considerar los vicios de la ley que aprobaba el referendo como irregularidades menores, o violación sustancial a la democracia liberal. El concepto del Procurador General de la Nación, Alejandro Ordoñez a la Corte Constitucional sobre la exequibilidad de la ley que aprueba el referendo, se sustenta principalmente en que las fallas en el trámite en el Congreso son menores y una segunda reelección no afecta la esencia de la Constitución Política; contrario sensu, la sentencia C-141-10 de la Corte Constitucional, proferida en ejercicio de la facultad de guarda de la Constitución Política, consagrada en el numeral 2 del artículo 241 C. N., prohíja una tesis según la cual existen (i) vicios en el trámite de la iniciativa legislativa ciudadana, (ii) Vicios en el procedimiento legislativo y, (iii) vicios competenciales o de exceso del poder de reforma constitucional que constituyen un desconocimiento de importantes principios constitucionales y de los procedimientos formales previstos por la Constitución; sostiene esta alta corporación que estos vicios no son meras irregularidades formales, sino violaciones sustanciales al principio democrático.

A esta altura de la propedéutica llevada a cabo en este trabajo, y después de señalar la tesis de la Procuraduría General y las razones de fondo (ratio decidendi) de la Corte Constitucional que examinan los vicios de la Ley 1354 de 2009, resulta pertinente intentar una proposición que sirva como referente a los desarrollos posteriores y argumentos de las razones que contribuyan a tomar una postura frente a las tesis aquí planteadas. En concordancia con lo predicho, se sostiene que la democracia no se agota en los procedimientos ni en la soberanía popular, el poder en las democracias postmodernas no solo necesitan ajustar sus decisiones a los procedimientos legales y constitucionales, sino que además se requiere de un control efectivo al poder, es decir, las decisiones se deben tomar conforme a los rituales de ley y los contenidos de dichas decisiones deben estar conforme a los principios y valores jurídicos constitucionales.

Un Estado que represente a todos los ciudadanos y un poder en cabeza de un monarca que opera con facultades ilimitadas otorgadas por el pueblo en el contrato que celebraron para que un tercero les garantizara sus derechos a través de una cesión de estos, constituye el fundamento iusfilosofico del absolutismo propuesto por T. Hobbes; frente a esta teoría contractualista, surge el contractualismo liberal de J. Locke, que observa el peligro de un poder absoluto del gobernante. Para J. Locke el gobernante no puede en ejercicio de un poder ilimitado, violar los derechos de los ciudadanos, como tampoco resulta correcto ceder derechos que son intransferibles, 
por lo tanto, el contrato que le da nacimiento al Estado no coloca en manos del gobernante poderes absolutos, por el contrario, establece límites a este.

Para J. J. Rousseau, autor del Contrato Social plantea que el poder del soberano una vez constituido por la voluntad de los ciudadanos es infalible, por lo tanto, no se requiere que este otorgue garantía a sus súbditos porque es improbable que el todo perjudique a las partes, y deja deslizar un razonamiento que tiene una fuerza que podríamos calificar como tenue, al sostener que el soberano no puede cargar con cadenas a la comunidad, no plantea una forma concreta de limite al poder.

Norberto Bobbio, al referirse a los límites del Estado, dice que esta expresión comprende dos aspectos, el primero hace referencia a los límites de los poderes y, el segundo a las funciones del Estado. El primero se refiere al estado de derecho, el segundo al estado mínimo. En el fondo lo que se expresa es la vieja concepción del iusnaturalismo, el gobernante no está sujeto a las leyes positivas, pero si a unos principios universalmente válidos, constituidos por los derechos humanos.

Las normas positivas del orden material eran meramente normas formales que él podía violar o desconocer, en este sentido la ley constituye un límite formal, no real o material. Pero en sentido fuerte, es decir moderno, el Estado de Derecho establece unos límites al poder cuando este aplica o lleva a cabo actuaciones que son ilegales, arbitrarias, obstaculizan el goce de los derechos humanos, en consecuencia existen unos mecanismos que frenan estos abusos del poder, por lo tanto, se establecen unos controles que ponen límites al ejecutivo, al legislativo, al poder judicial y al poder local. En este sentido la democracia en un estado liberal tiene unos límites, sin embargo la representación de los ciudadanos mediante la forma representativa, atomiza el Estado y presenta graves dificultades éticas, como la toma de decisiones en el Congreso, sin que los representantes consulten a sus representados, de esta forma se cumple con las normas jurídicas que establecen los procedimientos, estamos en este caso frente a una democracia formal, las decisiones se toman con apego a las ritualidades de la ley, pero al fallar la concordancia entre la voluntad de los representantes (senadores), con la de los representados (ciudadanos), encontramos una antinomia, realidad formal y realidad material.

Existen problemas mayores en torno a la democracia e igualdad, es aceptado por la doctrina que los Estados liberales deben ser democráticos y las democracias, liberales; empero el concepto de democracia encierra problemas relacionados con la participación del pueblo, de las mayorías, en este sentido, las democracias deben esforzarse por alcanzar al máximo el principio de igualdad, de soberanía popular, en ese sentido Bobbio, expresa: 
No sólo el liberalismo es compatible con la democracia, sino que la democracia puede ser considerada como el desarrollo natural del Estado liberal, a condición de que no se considere la democracia desde el punto de vista de su ideal igualitario sino desde el punto de vista de su fórmula política que, como se ha visto, es la soberanía popular. La única manera de hacer posible el ejercicio de la soberanía popular es la atribución al mayor número de ciudadanos del derecho de participar directa e indirectamente en la toma de las decisiones colectivas, es decir, la mayor extensión de los derechos políticos hasta el último límite del sufragio universal masculino y femenino, salvo el límite de la edad (1989, p, 41)

$Y$ es exactamente en este punto donde surgen los mayores problemas; el precitado autor dedica todo un capítulo de la obra Liberalismo y Democracia a este asunto y lo titula "La Tiranía de la mayoría" (Capítulo XI), en un sistema de este género, elegidos por ciudadanos, se sustenta en la centralización y la soberanía popular, se impone la fuerza del número, sobre la de los individuos, este principio de la mayoría es considerado por la doctrina como el principio igualitario, en consecuencia, el problema está relacionado con la naturaleza de las cosas licitas que hagan.

Otro autor emblemático en el mundo jurídico actual es Luigi Ferrajoli, quien en su trabajo "Democracia sin Estado", plantea una crisis del Estado, representada en la transferencia cada vez de mayores cuotas de poder al Derecho Privado, es decir, el Estado como órgano de Derecho Público, ha ido cediendo mayores poderes a los particulares. En este sentido, existen organismos de derecho internacional privado como Fondo Monetario Internacional (FMI), Organización Mundial del Comercio $(\mathrm{OMC})$, que han adquirido grandes poderes que le permiten definir políticas de la órbita exclusiva de cada Estado, violando de esta manera su soberanía; bajo este modelo no se consulta a los ciudadanos, como tampoco a los representantes del pueblo, de esta manera en estas esferas se toman decisiones esenciales que afectan la vida de los nacionales; son los organismos internacionales de derecho privado quienes deciden sobre asuntos trascendentales que inciden en la vida de las personas, en ese sentido, el concepto de soberanía ha quedado bajo examen en las actuales circunstancias de las relaciones internacionales del mundo global.

Lo que de manera autentica existe, es la crisis de lo público, del Estado en un extremo, y en el otro, el fortalecimiento de lo privado, de lo patrimonialistico. El Estado, lo público que tiene una función social, que busca el bienestar general, ha cedido al interés particular, y los procedimientos para tomar decisiones se hacen con apego a la ley, pero los contenidos de dichas decisiones van en contra del bienestar general. Por ello, en el órgano legislativo se pueden hacer leyes con observancia de los procedimientos, empero esas leyes no siempre buscan el bienestar general, así 
por ejemplo, el Acto Legislativo 01 de 2007, que reformo los artículos 356 y 357 de la Constitución Política, modifico la fórmula que había establecido el constituyente del 91, para la transferencia de los recursos que la nación debía enviar a los entes territoriales para financiar educación, salud y agua potable; el acto reformatorio se hizo conforme a los procedimientos establecidos por la propia Constitución y la ley, sin embargo, el contenido de la nueva norma vulnera los intereses de la comunidad y en especial de los más débiles, es un caso típico de un congreso que no legisla para el bien común, sin embargo las reformas son válidas porque se hicieron conforme a los rituales procesales establecidas por el derecho para hacer y aprobar dichas leyes.

El asunto de los procedimientos, es nodal en el examen de la democracia moderna, este aspecto lo encontramos en varios autores entre los cuales destacamos a Norberto Bobbio y Luigi Ferrajoli, en el primero, cuando sostiene "Los ideales liberales y el método democrático gradualmente se han entrelazado de tal manera que, si es verdad que los derechos de libertad han sido desde el inicio la condición necesaria para la correcta aplicación de las reglas del juego democrático, también es verdad que sucesivamente el desarrollo de la democracia se ha vuelto el instrumento principal de la defensa de los derechos de libertad ${ }^{4}$, , en el último, en el concepto de democracia procedimental desarrollado en el trabajo "Democracia sin Estado" donde sostiene:

Podemos llamar formal o procedimental a esta definición de la democracia. De hecho, ella identifica a la democracia únicamente sobre la base de las formas y de los procedimientos idóneos para garantizar la voluntad popular: en otras palabras, sobre la base del "quien" (el pueblo o sus representantes) y del "como" (la regla de la mayoría) de las decisiones, independientemente de sus contenidos, cualesquiera que ellos sean. Incluso un sistema en el cual se decidiese por mayoría la supresión de una minoría seria, a la luz de este criterio, "democrático"

Por excelencia lo que define a una democracia es el método, pero, se cuestiona si este puede ser el elemento que legitime a un sistema democrático. Si en un Estado se ha instituido el poder por medio de la participación popular, es decir a través del voto de los ciudadanos, pero este poder viola los derechos humanos, o se cambian las reglas establecidas dentro del ordenamiento jurídico para favorecer un interés particular, podemos preguntarnos, si ese Estado es democrático; la respuesta seguramente será contundente, no. La historia nos muestra casos en los

\footnotetext{
4 Ibid, pág. 41

5 FERRAJOLI, Luigi. Sobre el concepto de democracia. Una discusión con Michelangelo Bovero. En: www.cervantesvirtual.com/servlet/SirveObras/.../Isonomia_
} 
cuales, países que eligieron mediante el sufragio universal, es decir a través de un método democrático a un gobernante, este en el poder utiliza vías y procedimientos democráticos, establecidos en la ley para destruir la democracia, es algo así como, en nombre de la democracia destruyo la democracia, el ejemplo más conocido y funesto lo registra la historiografía como el nazismo.

Dentro de este contexto encontramos que la ley 1354 de 2009, recoge la voluntad de unas mayorías, pero la ley que aprobaba el referendo se hizo con violación de procedimientos establecidos por la constitución y la ley; las mayorías parlamentarias desconocieron los rituales procedimentales que debían cumplir en el trámite legislativo, es así como se incumplió con lo señalado por el artículo 27 de la Ley Estatutaria de Mecanismos de Participación, sobre cumplimiento de los requisitos exigidos para la realización de los mecanismos de participación ciudadana, entre otros, el cumplimiento de los topes globales e individuales de financiación, y el debate sobre la ley del referendo comenzó sin que fuera adjuntada la certificación del Registrador Nacional del Estado Civil.

De la misma manera se incumplió con del decreto 4742 de 2008, mediante el cual se convocaba a sesiones extraordinarias al Congreso de la República y la plenaria de la Cámara de Representantes se reunió cuando ese Decreto aún no había sido publicado en el Diario Oficial. Argumentar que estos vicios son irregularidades menores, constituye un desconocimiento del Estado de derecho fuerte, que garantiza el derecho que tienen los ciudadanos a exigir al gobernante el cumplimiento de la ley, y la obligación del poder a cumplir con las formalidades procesales; desde el punto de vista doctrinal y jurisprudencial los procedimientos no son meras formalidades, están en concordancia con las normas sustanciales, por ello, comportan la misma naturaleza.

Además de los vicios de procedimientos, existen los de fondo, sustanciales como el que vulnera el principio democrático, este se ve afectado con una segunda reelección, y consecuencialmente la arquitectura de la constitución y la democracia quedan fuertemente lesionadas, se produce una sustitución de la Constitución Política, por lo tanto una ley que convoque a un referendo que busca la reforma a la Constitución para que apruebe una segunda reelección, es claramente inconstitucional. Como se había dicho anteriormente, la dictadura de las mayorías no puede desconocer los derechos de las minorías, y es imperativo el cumplimiento de la constitución y la ley en el trámite de cualquier ley; la constitución establece los procedimientos para su reforma, tal como está señalado en el artículo 374 Constitución política, pero no establece estos procedimientos como válidos para la sustitución de nuestra norma superior. 
Se encuentra efectivamente que una segunda reelección afecta principios constitucionales que sustenta la estructura de nuestro sistema democrático constitucional, como la separación de los poderes, el sistema de controles, la regla de alternación y periodos establecidos, en este sentido la democracia como lo señala Bobbio, en sentido jurídico institucional y no en significado ético, tiene un sentido más procesal que sustancial, pero que al mismo tiempo en sentido ético, es decir sustancial encontramos en el caso de una segunda reelección en nuestro país se estaría debilitando la democracia liberal como una democracia de forma de igualdad, lo cual se manifiesta cuando un presidente-candidato tendría un gran poder y beneficios frente a ciudadanos-candidatos en condiciones débiles frente a la de aquel.

Como criterio personal considero que las teorías contractualistas y en relación con el sistema democrático fuerte y débil constituyen formas conceptuales que deforman la realidad, en atención a que no revelan la esencia de hechos históricos que sirven para explicar y comprender instituciones jurídico-políticas como las anteriormente señaladas. El Estado no es de naturaleza organicista como lo sostiene Aristóteles en la Política, como tampoco contractualista como lo afirman Rousseau, Hobbes, Locke, Montesquieu, por el contrario es un instrumento de quienes ostentan el poder para proteger sus prerrogativas y asegurar una seguridad jurídica. Con apoyo en lo anterior es fácil comprender como el derecho entendido como norma sustancial y adjetiva se encuentra formalmente establecido, su lugar está en los códigos, las leyes, en consecuencia conforma un sistema jurídico que se valida por sí mismo, su validez es conceptual, categorial, pero no necesariamente real, por ejemplo, el articulo $26 \mathrm{CP}$, a su voz expresa "Toda persona es libre de escoger profesión u oficio", en el plano de la razón, de la lógica se puede probar fácilmente esta tesis, pero este principio jurídico de jerarquía constitucional no resiste una comprobación empírica, verbi gracia, son numerosos los jóvenes que tienen capacidades cognitivas y desean estudiar ciertos programas costosos, sin embargo, la libre escogencia de profesión está determinada por otros factores, en especial, el económico. "Toda persona es libre para escoger profesión u oficio", es una verdad lógico-formal, más no una verdad verdadera. Sin embargo, decisiones como las de la Corte Constitucional, Sentencia C-141-10, resultan esperanzadoras, en el sentido del papel del derecho como instrumento capaz, de proporcionar justicia y transformaciones sociales, mediante estos actos se puede derrotar el escepticismo jurídico.

En conclusión, podemos afirmar que el proyecto de reforma constitucional que buscaba una segunda reelección presentaba anomalías de forma y fondo, lo cual hacía imposible pasar el tamiz de exequibilidad. Promover vía referendo una segunda reelección lesiona de manera grave la democracia desde el punto de vista de 
los contenidos de la reforma, los cuales sustituyen la estructura que sustenta nuestra constitución del 91, es decir, con el fallo C-141-10 de la Corte Constitucional se abre paso en nuestro país, la propuesta de Bobbio y Ferrajoli, en lo que tiene que ver con la democracia constitucional o sustancial, que sustituye el concepto de democrática procedimental o formal, y controla la tiranía de las mayorías.

\section{Referencias Bibliográficas}

- BOBBIO, Norberto. Liberalismo y democracia. Fondo de cultura económica. México. 1989.

- HART, H. L. A. El concepto de derecho. Abeledo Perrot. Argentina. 1961. Ley 1354 DE 2009

- REY CANTOR, Ernesto. Introducción al derecho procesal constitucional. Controles de constitucionalidad y legalidad. Universidad Libre, sede Cali. 1994.

- Sentencia C-141-10, Corte Constitucional 